University of Nebraska - Lincoln

DigitalCommons@University of Nebraska - Lincoln

2020

\title{
Communication Accommodation and Identity Gaps as Predictors of Relational Solidarity in Interfaith Family Relationships
}

Toni Morgan

Jordan Soliz

Mackensie Minniear

Gretchen Bergquist

Follow this and additional works at: https://digitalcommons.unl.edu/commstudiespapers

Part of the Critical and Cultural Studies Commons, Gender, Race, Sexuality, and Ethnicity in Communication Commons, and the Other Communication Commons

This Article is brought to you for free and open access by the Communication Studies, Department of at DigitalCommons@University of Nebraska - Lincoln. It has been accepted for inclusion in Papers in Communication Studies by an authorized administrator of DigitalCommons@University of Nebraska - Lincoln. 


\title{
Communication Accommodation and Identity Gaps as Predictors of Relational Solidarity in Interfaith Family Relationships
}

\author{
Toni Morgan, ${ }^{1}$ Jordan Soliz, ${ }^{2}$ \\ Mackensie Minniear, ${ }^{3}$ \& Gretchen Bergquist ${ }^{4}$ \\ 1 Doctoral Candidate, Department of Communication Studies, \\ University of Nebraska-Lincoln \\ 2 Professor, Department of Communication Studies, \\ University of Nebraska-Lincoln \\ 3 Doctoral Candidate, Department of Communication Studies, \\ University of Nebraska-Lincoln \\ 4 Assistant Professor, California State University, San Bernardino \\ Correspondence to: Toni Morgan, Department of Communication Studies, \\ University of Nebraska-Lincoln, 305 Louise Pound Hall, Lincoln, NE 68588- \\ 0329, USA. E-mail: toni.morgan@huskers.unl.edu
}

\begin{abstract}
Guided by Communication Accommodation Theory (CAT) and Communication Theory of Identity (CTI), the purpose of this study was to investigate how families communicatively negotiate religious differences and how that negotiation is related to parent-child relational solidarity. Specifically, we examined the direct effects of (non)accommodative communication on relational solidarity and indirect effects
\end{abstract}

Published in Communication Reports Vol. 33, No. 1, 2020, pp. 41-54.

DOI: $10.1080 / 08934215.2019 .1692052$

Copyright (C) 2019 Western States Communication Association. Published by Routledge/

Taylor \& Francis. Used by permission. 
via identity gaps. Using a cross-sectional survey from emerging adult college students $(\mathrm{N}=234)$, we found nonaccommodative communication is indirectly related to lower relational solidarity through increased identity gaps. Accommodative communication is indirectly related to higher relational solidarity through decreased identity gaps. When parents use accommodative strategies, they may help alleviate the mismatch between their child's personal, enacted, and relational layers of identity, and foster increased relational solidarity.

Keywords: Communication Accommodation, Family, Identity Gaps, Religious Difference

In recent years, scholars have recognized that issues of identity and difference exist even in more personal domains such as friendships (Capozza, Falvo, Trifiletti, \& Pagani, 2014) and families (Soliz \& Rittenour, 2012). Central to this line of inquiry is that communication can amplify or minimize the negative aspects of divergent identities and worldviews in these relationships. Interfaith marriages are increasing, and more children are deviating from the religion of their parents, especially in Western countries (Pew Forum on Religion and Public Life, 2008; Soliz \& Colaner, 2014). Given that religious identity is a salient aspect of many individuals' selfconcepts (Batson, 1982) and families are influenced by religious identity, often exuding significant effort in creating conformity among members (Edgell, 2005), communication in these family relationships concerning religion and faith has important implications for relational solidarity. Thus, integrating communication accommodation theory and communication theory of identity, the purpose of the current study is to examine how (non) accommodative communication relates to self-concept (i.e., identity gaps) and relational solidarity in interfaith parent-child relationships.

\section{(Non)accommodative Communication and Identity Gaps}

Communication accommodation theory (CAT; Dragojevic, Gasiorek, \& Giles, 2015) proposes that communication can magnify or minimize psychological and social distance in interactions. Accommodation reflects behaviors in which individuals appropriately attune communication to the perceived needs, desires, and/or expectations of the conversational partner. Conversely, nonaccommodation reflects behaviors that fail to adapt communication in a manner appropriate to the relationship or setting. 
In the context of interfaith families, Colaner, Soliz, and Nelson (2014) identify two accommodative and three nonaccommodative behaviors linked to relational solidarity. Religious-specific supportive communication occurs when individuals convey support and regard for the other's religious identity, even though it is dissimilar from their own. Respecting divergent values involves communicatively affirming another's religious identity and avoiding offensive comments. Inappropriate self-disclosure is the tendency for people to talk excessively about their religious experiences and beliefs without taking into account the different perspective of the listener. Emphasizing divergent values reflects communication that highlights areas of discrepancy or disagreement between religious identities and beliefs. Finally, giving unwanted advice occurs when individuals provide unsolicited advice and suggestions that are specifically grounded in religious beliefs that are not shared. Colaner and colleagues identify positive relational implications for religious-specific supportive communication and respecting divergent values, whereas inappropriate self-disclosure, emphasizing divergent values, and giving unwanted advice were linked with increased relational distance. With the goal of delving more into the communicative and cognitive process through which accommodative behaviors are linked to relational outcomes, we position identity gaps as a pathway through which (non)accommodation is associated with relational solidarity.

Based on communication theory of identity (CTI; Hecht, 2014), identity gaps are discrepancies between different components, or layers, of identity. Personal identity represents an individual's self-concept. Enacted identity is how individuals behave as an expression of identity. Relational identity is shaped by how relational partners view the individual as well as the relational unit's identity (i.e., family identity). For this study, we are interested in personal-enacted and personal-relational identity gaps and provide examples here as they pertain specifically to parent-child religious difference.

Personal-enacted identity gaps occur when individuals behave in ways that are not consistent with their self-concept. For example, individuals may feel they cannot express themselves in a way that reflects their personal religious identity. The personal-relational identity gap occurs when there is a discrepancy between one's self-concept and the identities ascribed to them by others, such as when an individual's family assumes she adheres to the family's religious identity 
when she does not. Identity gaps are consistently associated with negative individual and relational outcomes, such as depression (Jung \& Hecht, 2008), increased physiological reactions to stress (Merrill \& Afifi, 2017), and decreased relationship satisfaction (Kennedy-Lightsey, Martin, LaBelle, \& Weber, 2015).

Given that accommodative dimensions of communication in interfaith families (e.g., respecting divergent values) reflect a more personcentered orientation in which differences are respected and affirmed, we expect accommodation to minimize identity gaps in the family:

H1: Religious-specific supportive communication and respecting divergent values are negatively associated with the personalenacted and personal-relational identity gaps in interfaith families.

Conversely, the nonaccommodative dimensions of communication in interfaith families likely make these differences in the family more salient and, therefore, amplify identity gaps.

H2: Inappropriate self-disclosure, emphasizing divergent values, and giving unwanted advice are positively associated with the personal-enacted and personal-relational identity gaps in interfaith families.

Both (non)accommodation and identity gaps are associated with various individual and relational outcomes (Jung \& Hecht, 2004; Soliz \& Giles, 2014). For instance, religious disagreement on important theological issues is associated with more marital conflict (Curtis \& Ellison, 2002) and less stability (Chinitz \& Brown, 2001). Religious difference also can occur between parents and children, especially as children mature and develop their own beliefs about the world around them. Not surprisingly, religious difference and nonaccommodative communication between parents and children are associated with decreased satisfaction and shared family identity (Colaner et al., 2014). Because of the frequent relationship strain interfaith family relationships experience, we chose to focus on perceived relational solidarity in the present study, which "reflects relational satisfaction and closeness, liking, commonality, and trust" (Imamura, Zhang, \& 
Harwood, 2011, p. 108). Relational solidarity is particularly important when family members experience significant religious differences that may highlight out-group distinctions (Soliz \& Harwood, 2006) as it emphasizes a satisfying family bond that members share. Based on the tenets of CAT and CTI, we propose the following hypotheses:

H3: Religious-specific supportive communication and respecting divergent values are positively associated with relational solidarity in interfaith families.

H4: Inappropriate self-disclosure, emphasizing divergent values, giving unwanted advice, personal-enacted identity gaps, and personal-relational identity gaps are negatively associated with relational solidarity in interfaith families.

The preceding hypotheses suggest that, in addition to direct effects of accommodative and nonaccommodative behaviors, these behaviors may also predict relational solidarity via identity gaps. Therefore, we propose the final hypothesis:

H5: Religious-specific supportive communication, respecting divergent values, inappropriate self-disclosure, emphasizing divergent values, and giving unwanted advice will have indirect effects on relational solidarity via identity gaps in interfaith families.

\section{Method}

\section{Participants}

After receiving approval from the Institutional Review Board, participants $(N=330)$ were recruited from undergraduate communication courses in a large university in the United States. Participants were required to be at least 19 years old (the legal age of majority in the state where the study was conducted) and identify a significant religious difference between themselves and their parent(s). We assessed religious difference in two ways. First, participants responded 
to a 5-item measure developed for this study in which higher scores indicated more religious similarity. ${ }^{1}$ Second, participants provided open-ended responses labeling their religious identity as well as their parent(s)'s. Based on the openended responses, three main patterns of religious difference emerged: interfaith (i.e., Catholic-Jewish), intrafaith (i.e., Catholic-Methodist), and intradenominational (i.e., Catholic-(atholic). We only retained those participants that were either coded as being interfaith or who were intrafaith or intradenominational and reported average or below average religious similarity on all five scale items. In this way, we included a variety of religious difference experiences. Some participants identified as atheist or agnostic while their parent(s) identified as evangelical Christian. Others may have identified with the same religious tradition as their parent but had different worldviews on specific issues (e.g., social issues such as abortion or same-sex marriage) that manifested in perceptions of salient religious difference in the family. We retained 234 participants after this process, 127 participants with interfaith differences, 63 participants with intrafaith differences, and 44 participants with intradenominational differences. Participants reported an average religious similarity score of $2.75(S D=0.93)$.

After going through this process, the final sample consisted of 129 females and 105 males ranging in age from 19 to $45(M=20.46, S D=$ 2.56), reflecting a variety or religious identities, faiths, and/or orientations, including atheist/agnostic identity. The majority of participants identified as White or Caucasian $(n=172)$, but the sample also included participants who identified as Asian/Middle Eastern ( $n=$ $31)$, multiracial $(n=14)$, Black or African American $(n=7)$, and Hispanic/Latino $(n=7)$. Three participants did not identify their racial/ ethnic identity.

\section{Measurement}

After agreeing to an informed consent statement, participants completed an online questionnaire. All measures were completed on 5 -point scales $(1=$ strongly disagree to $5=$ strongly agree $)$. Alphas and number of scale items all refer to the final versions of the scales included in the analyses reported in this study. Descriptive statistics and intercorrelations between all variables are provided in Table 1. 
Table 1 Descriptive Statistics and Intercorrelations $(N=234)$

\begin{tabular}{|c|c|c|c|c|c|c|c|}
\hline & M & SD & 1 & 2 & 3 & 4 & 5 \\
\hline 1. Accommodative communication & 3.63 & 0.88 & - & & & & \\
\hline 2. Nonaccommodative communication & 2.46 & 0.81 & $-.522 *$ & - & & & \\
\hline 3. Personal-enacted identity gap & 2.40 & 0.79 & $-.477^{\star}$ & $.447^{*}$ & - & & \\
\hline 4. Personal-relational identity gap & 2.07 & 0.63 & $-.443^{*}$ & $.494^{*}$ & $.703^{*}$ & - & \\
\hline 5. Relational solidarity & 4.18 & 0.68 & $.497^{*}$ & $-.447^{\star}$ & $-.616^{\star}$ & $-.631^{\star}$ & - \\
\hline
\end{tabular}

\section{(Non)accommodation}

The five dimensions of accommodative and nonaccommodative behaviors were assessed with Colaner et al.'s (2014) original scale. ${ }^{2}$ To assess if these are five distinct constructs, a series of confirmatory factor analyses (CFA) were conducted with results suggesting the items from the original scale better reflect two global dimensions of accommodative and nonaccommodative behaviors related to perceptions of religious-oriented communication from parents: accommodative communication (7 items, e.g., "My parents let me know that they support my right to choose my own religious beliefs," $\alpha=.93$ ) and nonaccommodative communication (11 items, e.g., "My parents express disapproval over my religious choices," $\alpha=.90$ ); RMSEA $=.073$ (Browne \& Cudeck, 1993), CFI = .947 (Bentler, 1990), SRMR = .o6o $(\mathrm{Hu} \&$ Bentler, 1999). Higher scores reflect higher levels of accommodation or nonaccommodation.

\section{Identity Gaps}

The personal-enacted identity gap and personal-relational identity gap were assessed using scales from Jung and Hecht's (2004) original measures. Divergent validity of the identity gap measures (i.e., are the scales assessing distinct constructs via the items) was assessed via a CFA resulting in exclusion of two items from the personal relational identity gap measure for acceptable model fit: personal-relational identity gap (10 items, e.g., "I feel that my parent(s) have wrong images of me," $\alpha=.89$ ) and personal-enacted identity gap (11 items, e.g., "I feel that I can be myself when communicating with my parent(s)," $\alpha=.92)$; RMSEA = .063, CFI = .943, SRMR = .054 Higher scores reflect higher levels of each identity gap. ${ }^{3}$ 


\section{Relational Solidarity}

Relational solidarity measured with an 8-item condensed version of Wheeless (1976) Interpersonal Solidarity Scale. Higher scores indicated more relational solidarity (e.g., "In general, I am very satisfied with my relationship with my parent(s)," and "I trust my parent(s)," $\alpha=.77)$.

\section{Results}

Based on the preliminary analysis of the (non)accommodative dimensions, we tested a parallel mediation model assessing direct and indirect effects (see Figure 1) with Mplus 7 software (Muthén \& Muthén, 2012). This model hypothesizes that accommodation and non-accommodation are both indirectly and directly related to relational solidarity via the personal-relational and personal-enacted identity gap. Because the model was just identified, the global fit was perfect. The means of each scale were used as observed variables in the final model. See Table 1 for all zero-order correlations and Table 2 for a summary of the direct and indirect effects with 95\% confidence intervals.

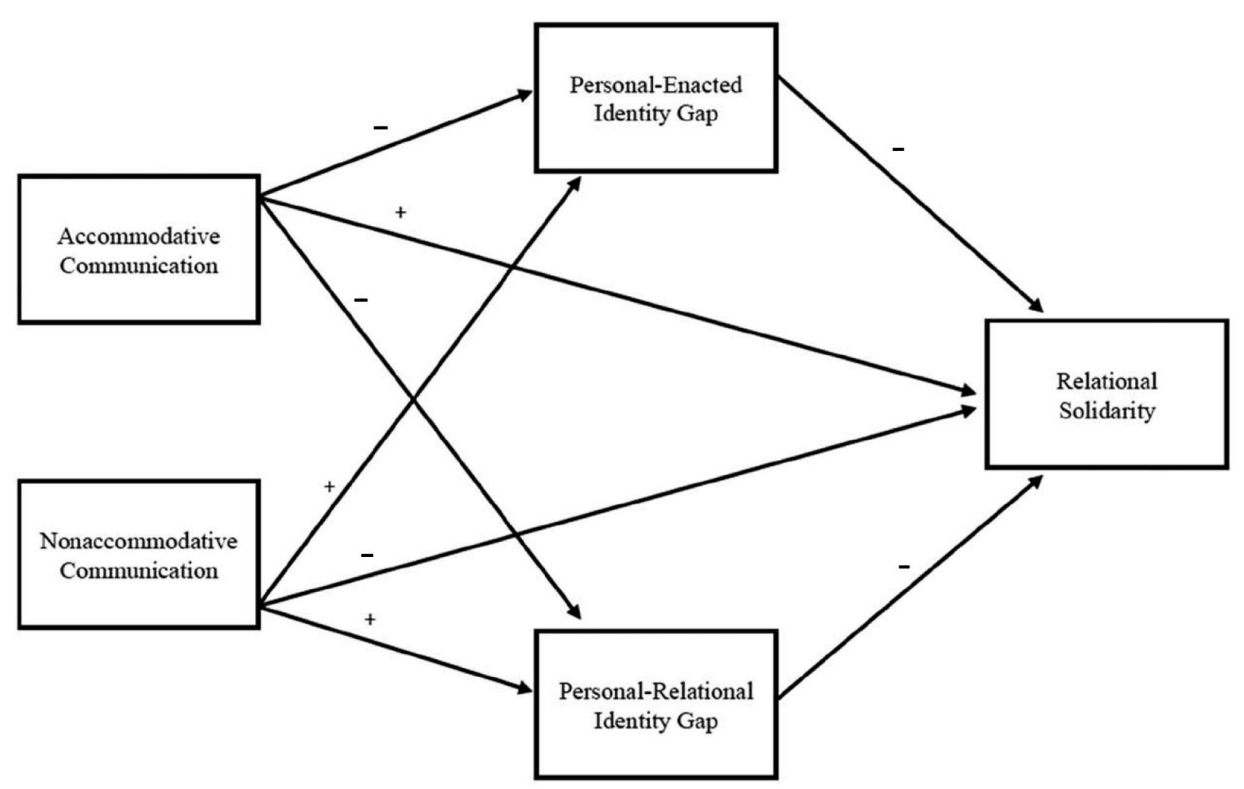

Figure 1. Conceptual path model. Covariance between (non)accommodative constructs and between identity gap constructs not depicted. 


\section{Direct Effects}

Supporting $\mathrm{H} 1$ and $\mathrm{H} 2$, there was a direct negative effect of accommodative communication on personal-relational and personal-enacted identity gaps, whereas non-accommodation had a positive direct effect on each identity gap. There also was a direct positive effect between accommodation and relational solidarity supporting H3. Non-accommodation was not significantly directly associated with relational solidarity. However, both identity gaps emerged as negative predictors of relational solidarity. Thus, when accounting for both (non)accommodative behaviors and identity gaps in tandem, there was only partial support for $\mathrm{H}_{4}$.

\section{Indirect Effects}

Finally, there were significant indirect effects for both accommodation and non-accommodation on relational solidarity supporting the accommodative-identity gap pathway ( $\mathrm{H}_{5}$ ). A bootstrap approach (Shrout \& Bolger, 2002) was implemented. Bootstrapping provides an empirical approximation of sampling distributions of indirect effects to produce confidence intervals (CI) of estimates. If zero does not fall within the CI, we can assume the indirect effect is different from zero. We performed a nonparametric resampling method (biascorrected bootstrap) with 5000 resamples drawn to derive 95\% CIs for all indirect effects (see Table 2). Accommodative communication was associated with minimal presence of each identity gap, which, in turn, was associated with less relational solidarity. Conversely, nonaccommodative behaviors were associated with increased identity gaps and, as such, less relational solidarity. Overall, the model predicted notable variance for each endogenous variable: personal-enacted identity gap (.281), personal-relational identity gap (.288), relational solidarity (.494).

\section{Discussion}

Similar to other intergroup contexts, intergroup dynamics in the family can lead to negative relational outcomes (Colaner et al., 2014). 
Table 2 Model Parameters: Factor Loadings, Total Effects, Direct Effects, and Indirect Effects

\begin{tabular}{|c|c|c|c|}
\hline & $\begin{array}{c}\text { Standardized } \\
\text { Coefficient }\end{array}$ & \multirow[t]{2}{*}{$\begin{array}{c}\text { CI Lower } \\
2.5 \%\end{array}$} & \multirow[t]{2}{*}{$\begin{array}{r}\mathrm{Cl} \text { Upper } \\
2.5 \%\end{array}$} \\
\hline Total Effects & & & \\
\hline Accommodation $\rightarrow$ Relational solidarity & .368 & .229 & .500 \\
\hline Nonaccommodation $\rightarrow$ Relational solidarity & -.250 & -.380 & -.127 \\
\hline \multicolumn{4}{|l|}{ Direct Effects } \\
\hline Accommodation $\rightarrow$ Personal-enacted ID gap & -.338 & -.473 & -.201 \\
\hline Accommodation $\rightarrow$ Personal-relational ID gap & -.256 & -.389 & -.111 \\
\hline Accommodation $\rightarrow$ Relational solidarity & .196 & .065 & .325 \\
\hline Nonaccommodation $\rightarrow$ Personal-enacted ID gap & .269 & .130 & .388 \\
\hline Nonaccommodation $\rightarrow$ Personal-relational ID gap & .357 & .232 & .481 \\
\hline *Nonaccommodation $\rightarrow$ Relational solidarity & -.061 & -.179 & .050 \\
\hline Personal-enacted ID gap $\rightarrow$ Relational solidarity & -.253 & -.432 & -.087 \\
\hline Personal-relational ID gap $\rightarrow$ Relational solidarity & -.339 & -.500 & -.178 \\
\hline Accommodation $\leftarrow \rightarrow$ Nonaccommodation & -.519 & -.619 & -.400 \\
\hline Personal-enacted ID gap $\leftarrow$ Personal-relational ID gap & .591 & .463 & .688 \\
\hline \multicolumn{4}{|l|}{ Indirect Effects } \\
\hline Accommodation $\rightarrow$ Personal-enacted ID gap $\rightarrow$ Relational solidarity & .086 & .029 & .171 \\
\hline Accommodation $\rightarrow$ Personal-relational ID gap $\rightarrow$ Relational solidarity & .087 & .033 & .169 \\
\hline Nonaccommodation $\rightarrow$ Personal-enacted ID gap $\rightarrow$ Relational solidarity & -.068 & -.137 & -.022 \\
\hline Nonaccommodation $\rightarrow$ Personal-relational ID gap $\rightarrow$ Relational solidarity & -.121 & -.207 & -.062 \\
\hline
\end{tabular}

As we demonstrated in this study, the potential negative effects of interfaith distinctions likely depend on the nature of parent-child interactions. Our discussion addresses the role of (non) accommodative behavior in interfaith families. We follow with a discussion of implications for identity gaps and considerations for future inquiries into religious identity difference in the family. We conclude with a discussion of limitations of the current study.

\section{(Non)accommodative Communication and Interfaith Families}

Findings from the current study suggest accommodative behaviors create a more positive relational context and have implications for individual self-concept (i.e., identity gaps) and well-being. Whereas nonaccomodative behaviors were associated with identity gaps, there was not a significant direct association with relational solidarity when 
also taking into account accommodation. Perhaps positive, person centered communication (i.e., accommodation) carries more weight when directly related to religious difference in the family. In other words, family members (and individuals in general) have been socialized to accept a social norm in which talking about differences should be tense, uncomfortable, or avoided. When family members enact accommodative communication through religious specific supportive communication and respecting divergent values, children may feel that this violates the social norm of conversational difficulty, and therefore, it may stand out as the most salient contributing factor to their relational solidarity. An important direction for future research, then, is to investigate the role of communicative social norms concerning religious difference in the family.

As scholars continue to move forward in understanding the role of communication in potentially ameliorating negative consequences of religious and faith-based differences in the family, it will be important to further investigate the distinctions, if any, between the five (non)accommodation behaviors originally proposed by Colaner et al. (2014) given the high correlations evident in the current study. In doing so, more recent theorizing on communication accommodation theory such as work focusing on the role of perceived motives for (non) accommodative behavior (Gasiorek \& Giles, 2015) may provide additional insight into the cognitive and communicative mechanisms at play as they relate to individual (e.g., identity gaps) and relational outcomes. For instance, believing a family member's non-accommodation is motivated by a desire to sustain family identity as opposed to a desire to change religious identities may differentiate the magnitude of the negative effects of nonaccommodative behaviors. Future research should investigate more of these potential nuances in behavior and motivation.

\section{Identity Gaps and Interfaith Families}

Religious identity is a salient characteristic of some families, and many parents spend a great deal of effort in creating a shared religious identity in the family. Supporting the tenets of CTI (Hecht, 2014), identity gaps in the family have negative consequences for family relationships. Put simply, if a child feels that they cannot be their "true" self in family relationships, there are consequences for family relationships. 
By integrating CAT and CTI, we demonstrated that identity gaps might not emerge simply because of a difference. Rather, they are associated with the manner in which we discuss the difference.

Given the scope of CTI, there are opportunities to integrate other identity gaps to further our understanding of the potential effects of religious difference in the family. For instance, an additional identity gap of interest is the personal-communal identity gap. Personal religious identity is often heavily motivated and informed by religious communities. With those communal commitments comes the pressure to adhere to certain beliefs and practices. When a highly religious family has a child who is atheist or agnostic, it may challenge parents' understanding of their own religious identity and create a discrepancy between their personal and their communal identity. For example, in a conservative fundamentalist protestant family, openly affirming a child's LGBTQ + identity may create tension in the family's participation in a church leadership position. Future research on identity gaps in interfaith families ought to further investigate this and other identity gaps.

Overall, the findings from our investigation of the interplay between (non)accommodation and identity gaps point to the importance of how we talk about difference, which is an increasingly important point in research on other intergroup relationships in and outside of the family. In fact, much of the work on intergroup dialogue (e.g., Dessel, Rogge, \& Garlington, 2006) demonstrates the importance of constructive discussion concerning difference as a way to ameliorate the personal and relational consequences of salient differences (such as religion) in our families. Supporting work by Colaner et al. (2014) and others (Soliz \& Rittenour, 2012), identity difference in the familyeven with important aspects of self, such as religion-is not inherently negative or problematic. The consequences of difference are constituted in our communication. Thus, rather than focusing on minimizing difference in personal relationships, we should continue to focus on how communication (in this case (non) accommodative behaviors) facilitates these positive outcomes and the process through which this takes place. As we demonstrate in this inquiry, identity gaps are an indirect part of this process, and there are potentially beneficial, malleable family practices (i.e., accommodative communication strategies) that can be taught, learned, and enacted to mitigate the severity of identity gaps. 


\section{Religious Difference in the Family}

In the current study, we focused generally on religious difference in the family as perceived by the family member. Religious identity is a very complex and nuanced aspect of self. Whereas we often conceptualize interfaith distinctions on a more macro-religious level (e.g., Christian/Jewish), participants in our study support the significance of within-group religious difference (e.g., liberal Christian theology and practice vs. traditional-conservative Christian theology and practice). In short, relationships in interfaith families may be influenced by intergroup distinctions (i.e., different religious identities) and/or different value orientations within a religious group. As scholars and practitioners continue to assess the effects of religious difference in the family, we also should look for potential distinctions between these macro-level differences versus within-group religious differences. Likewise, we should consider the role of religious orientations (i.e., extrinsic, intrinsic: Allport \& Ross, 1967; Batson \& Schoenrade, 1991) in understanding divergent religious identity in personal relationships as these orientations often dictate religious identity, religious behavior, and interfaith attitudes. In short, it is possible religious differences manifest differently or have different outcomes based on orientation.

Finally, based on the tenets of intergroup contact theory (Pettigrew, 1998), previous research suggests interactions in the family can change attitudes toward social outgroups (e.g., age attitudes can be improved by positive relations with grandparents; Harwood, Hewstone, Paolini, \& Voci, 2005). As such, there is an opportunity to examine how interfaith attitudes, in general, are associated with the manner families talk about their own interfaith differences.

\section{Limitations}

As with any empirical inquiry, there are limitations that should be considered in interpreting results and as additional opportunities for future research. First, the study focused on the adult child's perspective on religious difference and parental communication. Future research should consider both parent-child perceptions of difference and the communication that occurs to understand the dyadic nature of interactions. Additionally, scholars also should focus on potential 
variations in parent-child dynamics when the religious difference is between one or both parents. Second, the study relied on a convenience sample of university students. These students did experience and discuss their religious difference in the family, and there is a great deal of public discourse about parent-child religious difference upon entering college. As such, the experience shared is still valuable to this area inquiry; however, university students may be more reflective of and attuned to differences given the climate and discussions on college campuses. Thus, non-university populations may provide additional insight into how religious difference and communication function in the family.

Third, the sample was fairly homogenous in terms of ethnic-racial variation in the sample. Given different ethnic-racial groups experience religion differently (e.g., Grant, 2007), the relational consequences and role of communication could vary across ethnic-racial groups. Finally, our indirect effects are based on cross-sectional data. While there is a logical theoretical and temporal argument to be made for these pathways, there are limitations to the claims of causality and mediation. Thus, in line with Goodboy and Kline (2017) recommendation that communication scholars use structural equation modeling to replicate studies with independent samples, we view these findings as foundational to supporting longitudinal or other designs that allow for more explicit assessment of these directional pathways between (non)accommodative communication, identity gaps, and relational outcomes.

\section{Conclusion}

As the prevalence of religious difference and disagreement between parents and children rises, it is important to consider how parentchild interactions relate to individual and relational well-being. The purpose of this study was to investigate possible pathways through which (non)accommodative communication is associated with relational solidarity in interfaith parent-child relationships, namely, personal-enacted and personal relational identity gaps. Our findings suggest that (non)accommodative communication is indirectly related to relational solidarity through identity gaps. In other words, when 
parents use more accommodative strategies in discussing (or not discussing) religious differences with their children, they help alleviate the mismatch between their child's personal, enacted, and relational layers of identity, and thereby foster increased relational solidarity.

\section{Disclosure - No potential conflict of interest was reported by the authors.}

\section{Notes}

1. Items included, "I feel like my religious ideas are very similar to my parent(s)' religious ideas," "My religious beliefs are not at all like my parent(s)' beliefs" (reverse coded), "I basically believe the same things that my parent(s) does," "I really identify with my parent(s)' religion," and "I do not consider myself to share any religious beliefs with my parent(s)" (reverse coded). Items were measured on a 1 (strongly disagree) to 5-point (strongly agree) scale where higher scores indicated higher religious similarity. The scale was internally consistent ( $\alpha=$ .85 ). We tested to see if religious similarity moderated the relationship between (non)accommodation and identity gaps. There was no significant moderation effect, so this variable was removed from the model.

2. Due to concerns about convergent and divergent validity between accommodative and nonaccommodative communication, a religious-specific supportive communication item was removed from original religious specific supportive subscale for the final accommodation construct: "It is difficult to talk to my parent(s) about my religious beliefs because they think my beliefs are wrong."

3. The two items were removed from the personal-relational identity gap scale were "I feel that my parent(s) have correct information about me" and "I feel that my parent(s) know who I used to be when they portray me."

\section{References}

Allport, G. W., \& Ross, J. M. (1967). Personal religious orientation and prejudice. Journal of Personality and Social Psychology, 5, 432-443. doi:10.1037/hoo21212

Batson, C. D., \& Schoenrade, P. A. (1991). Measuring religion as quest: 1) Validity concerns. Journal for the Scientific Study of Religion, 30, 416429. doi:10.2307/1387277 Batson, D. (1982). Religion and the individual. New York, NY: Oxford University Press.

Bentler, P. M. (1990). Comparative fit indexes in structural models. Psychological Bulletin, 107, 238-246. doi:10.1037//0033-2909.107.2.238 
Browne, M. W., \& Cudeck, R. (1993). Alternative ways of assessing model fit. In K. A. Bollen \& J. S. Long (Eds.), Testing structural equation models (pp. 136-162). Newbury Park, CA: Sage. Capozza, D.

Falvo, R., Trifiletti, E., \& Pagani, A. (2014). Cross-group friendships, extended contact, and humanity attributions to homosexuals. Procedia-Social and Behavioral Sciences, 114, 276-282. doi:10.1016/j.sbspro.2013.12.698

Chinitz, J. G., \& Brown, R. A. (2001). Religious homogamy, marital conflict, and stability in same-faith and interfaith Jewish marriages. Journal for the Scientific Study of Religion, 40, 723-733. doi:10.1111/0021-8294.00087

Colaner, C. W., Soliz, J., \& Nelson, L. R. (2014). Communicatively managing religious identity difference in parent-child relationships: The role of accommodative and nonaccommodative communication. Journal of Family Communication, 14, 310-327. doi:10.1080/ 15267431.2014.945700

Curtis, K. T., \& Ellison, C. G. (2002). Religious heterogamy and marital conflict: Findings from the national survey of families and households. Journal of Family Issues, 23, 551-576. doi:10.1177/0192513x02023004005

Dessel, A., Rogge, M. E., \& Garlington, S. B. (2006). Using intergroup dialogue to promote social justice and change. Social Work, 51, 303-315. doi:10.1093/ $\mathrm{sw} / 51.4 \cdot 303$

Dragojevic, M., Gasiorek, J., \& Giles, H. (2015). Communication accommodation theory. In Eds. (C. R. Berger, M. Roloff, S. R. Wilson, J. P. Dillard, J. Caughlin, \& D. Solomon), The international encyclopedia of interpersonal communication. doi:10.1002/9781118540190. wbeicoo6

Edgell, P. (2005). Religion and family in a changing society. Princeton, NJ: Princeton University Press.

Gasiorek, J., \& Giles, H. (2015). The role of inferred motive in processing nonaccommodation: Evaluation of communication and speakers. Western Journal of Communication, 79, 456-471. doi:10.1080/10570314.2015.1066030

Goodboy, A. K., \& Kline, R. B. (2017). Statistical and practical concerns with published communication research featuring structural equation modeling. Communication Research Reports, 34, 68-77. doi:10.1080/o8824096.2016.1214121

Grant, J. (2007). White women's Christ and black women's Jesus. In K. Bagley \& K. McIntosh (Eds.), Women's studies in religion: A multicultural reader (pp. 4854). New York, NY: Taylor \& Francis.

Harwood, J., Hewstone, M., Paolini, S., \& Voci, A. (2005). Grandparentgrandchild contact and attitudes towards older adults: Moderator and mediator effects. Personality and Social Psychology Bulletin, 31, 393-406. doi:10.1177/0146167204271577

Hecht, M. L. (2014). Communication theory of identity: Multilayered understandings of performed identities. In D. O. Braithwaite \& P. Schrodt (Eds.), Engaging theories in interpersonal communication (pp. 175-188). Thousand Oaks, CA: Sage. 
Hu, L., \& Bentler, P. M. (1999). Cutoff criteria for fit indexes in covariance structure analysis: Conventional criteria versus new alternatives. Structural Equation Modeling: A Multidisciplinary Journal, 6, 1-55. doi:10.1080/10705519909540118

Imamura, M., Zhang, Y. B., \& Harwood, J. (2011). Japanese sojourners' attitudes toward Americans: Exploring the influences of communication accommodation, linguistic competence, and relational solidarity in intergroup contact. Journal of Asian Pacific Communication, 21, 103-120. doi:10.1075/ japc.21.1.ogima

Jung, E., \& Hecht, M. L. (2004). Elaborating the communication theory of identity: Identity gaps and communication outcomes. Communication Quarterly, 52, 265-283. doi:10.1080/ 01463370409370197

Jung, E., \& Hecht, M. L. (2008). Identity gaps and level of depression among Korean immigrants. Health Communication, 23, 313-325. doi:10.1080/10410230802229688

Kennedy-Lightsey, C. D., Martin, M. M., LaBelle, S., \& Weber, K. (2015). Attachment, identity gaps, and communication and relational outcomes in marital couples' public performances. Journal of Family Communication, 15, 232-248. doi:10.1080/15267431.2015.1043430

Merrill, A. F., \& Afifi, T. D. (2017). Couple identity gaps, the management of conflict, and biological and self-reported stress in romantic relationships. Human Communication Research, 43, 363-396. doi:10.1111/ hcre.12110

Muthén, L., \& Muthén, B. (2012). Mplus user's guide (7th ed.). Los Angeles, CA: Muthén \& Muthén.

Pettigrew, T. F. (1998). Intergroup contact theory. Annual Review of Psychology, 49, 65-85. doi:10.1146/annurev.psych.49.1.65

Pew Forum on Religion and Public Life. (2008). U.S. religious landscape survey. Washington, DC: Pew Research Center.

Shrout, P. E., \& Bolger, N. (2002). Mediation in experimental and nonexperimental studies: New procedures and recommendations. Psychological Methods, 7, 422-445. doi:10.1037// 1082-989x.7.4.422

Soliz, J., \& Colaner, C. W. (2014). Family solidarity and religious identity: Communication in interfaith families. In L. Turner \& R. West (Eds.), The Sage handbook of family communication (pp. 401-416). Thousand Oaks, CA: Sage.

Soliz, J., \& Giles, H. (2014). Relational and identity processes in communication: A contextual and meta-analytical review of communication accommodation theory. In E. Cohen (Ed.), Communication yearbook (Vol. 38, pp. 108-143). Thousand Oaks, CA: Sage.

Soliz, J., \& Harwood, J. (2006). Shared family identity, age salience, and intergroup contact: Investigation of the grandparentgrandchild relationship. Communication Monographs, 73, 87-107. doi:10.1080/03637750500534388 
Soliz, J., \& Rittenour, C. E. (2012). Family as an intergroup arena. In H. Giles (Ed.), The handbook of intergroup communication (pp. 331-343). New York, NY: Routledge.

Wheeless, L. R. (1976). Self-disclosure and interpersonal solidarity: Measurement, validation, and relationships. Human Communication Research, 3, 47-

61. doi:10.1111/j.1468-2958.1976.tboo503.x 